\title{
N-Wasp Regulates Oligodendrocyte Myelination
}

\author{
Christina Katanov, ${ }^{1}$ Nurit Novak, ${ }^{1}$ Anya Vainshtein, ${ }^{1}$ Ofra Golani, ${ }^{2}$ Jeffery L. Dupree, ${ }^{3}$ and ${ }^{\circledR}$ Elior Peles ${ }^{1}$ \\ ${ }^{1}$ Department of Molecular Cell Biology, Weizmann Institute of Science, Rehovot, 76100, Israel, ${ }^{2}$ Department of Life Sciences Core Facilities, \\ Weizmann Institute of Science, Rehovot, 76100, Israel, and ${ }^{3}$ Department of Anatomy and Neurobiology, Virginia Commonwealth University, \\ Richmond, Virginia 23284
}

Oligodendrocyte myelination depends on actin cytoskeleton rearrangement. Neural Wiskott-Aldrich syndrome protein (N-Wasp) is an actin nucleation factor that promotes polymerization of branched actin filaments. N-Wasp activity is essential for myelin membrane wrapping by Schwann cells, but its role in oligodendrocytes and CNS myelination remains unknown. Here we report that oligodendrocytes-specific deletion of $\mathrm{N}$-Wasp in mice of both sexes resulted in hypomyelination (i.e., reduced number of myelinated axons and thinner myelin profiles), as well as substantial focal hypermyelination reflected by the formation of remarkably long myelin outfolds. These myelin outfolds surrounded unmyelinated axons, neuronal cell bodies, and other myelin profiles. The latter configuration resulted in pseudo-multimyelin profiles that were often associated with axonal detachment and degeneration throughout the CNS, including in the optic nerve, corpus callosum, and the spinal cord. Furthermore, developmental analysis revealed that myelin abnormalities were already observed during the onset of myelination, suggesting that they are formed by aberrant and misguided elongation of the oligodendrocyte inner lip membrane. Our results demonstrate that N-Wasp is required for the formation of normal myelin in the CNS. They also reveal that N-Wasp plays a distinct role in oligodendrocytes compared with Schwann cells, highlighting a difference in the regulation of actin dynamics during CNS and PNS myelination.

Key words: actin dynamics; axon-glia; myelin; oligodendrocyte; Schwann cell

Significance Statement

Myelin is critical for the normal function of the nervous system by facilitating fast conduction of action potentials. During the process of myelination in the CNS, oligodendrocytes undergo extensive morphological changes that involve cellular process extension and retraction, axonal ensheathment, and myelin membrane wrapping. Here we present evidence that N-Wasp, a protein regulating actin filament assembly through Arp $2 / 3$ complex-dependent actin nucleation, plays a critical role in CNS myelination, and its absence leads to several myelin abnormalities. Our data provide an important step into the understanding of the molecular mechanisms underlying CNS myelination.

\section{Introduction}

Myelin is a specialized membrane produced by oligodendrocytes and Schwann cells that spiral around axons, thereby enabling fast conduction of action potentials, and providing axonal support (Nave and Werner, 2014; Cohen et al., 2020). During myelination in the CNS, oligodendrocytes undergo extensive morphological changes (Bauer et al., 2009; Seixas et al., 2019;

\footnotetext{
Received Apr. 19, 2020; accepted May 20, 2020.

Author contributions: C.K., N.N., and A.V. performed research; C.K., N.N., A.V., O.G., J.L.D., and E.P. analyzed data; C.K., N.N., A.V., and J.L.D. edited the paper; E.P. designed research; E.P. wrote the paper.

This work was supported by National Institutes of Health R01NS097428; Dr. Miriam and Sheldon G. Adelson Medical Research Foundation; National American Brain Foundation research grant; Lilly Fulop Fund for Multiple Sclerosis Research; Estates of David Georges Eskinazi, Dahlia and Philip Lawee, Gary Clayman, and Ellie Adiel; and Veterans Administration Merit Review Award 1101BX002565-05. E.P. is the Incumbent of the Hanna Hertz Professorial Chair for Multiple Sclerosis and Neuroscience.

The authors declare no competing financial interests.

Correspondence should be addressed to Elior Peles at peles@weizmann.ac.il.

https://doi.org/10.1523/JNEUROSCI.0912-20.2020

Copyright $\odot 2020$ the authors
}

Brown and Macklin, 2020), beginning with the formation of exploratory processes that either make stable axonal contact or retract (Czopka et al., 2013; Almeida and Lyons, 2014). This initial contact is then followed by membrane ensheathment and wrapping, longitudinal extension of the forming myelin unit, and compaction of the myelin membrane layers (Osso and Chan, 2017; Stadelmann et al., 2019). Oligodendrocytes contain two major cytoskeletal systems, microtubules and actin filaments, which regulate process formation and myelination (Bauer et al., 2009; Seixas et al., 2019; Brown and Macklin, 2020). The actin cytoskeleton has a higher turnover and reorganization rate than microtubules, enabling fast reshaping of myelinating oligodendrocytes (Song et al., 2001). Microtubules provide support to the morphology of the cell and allow transport of myelin-specific proteins and mRNA (Lunn et al., 1997; Seiberlich et al., 2015). Moreover, microtubules and actin filaments interact with each other, leading to oligodendrocyte process outgrowth (Song et al., 2001). Previous studies highlight the role of actin dynamics during myelin formation and suggest a two-step model. First, 
oligodendrocyte process outgrowth and the initial ensheathment of the axon are driven by Arp2/3 complex-dependent actin polymerization (Zuchero et al., 2015). Subsequently, lateral spreading and growth of the myelin membrane during wrapping and compaction requires F-actin disassembly by ADF/cofilin-1 (Nawaz et al., 2015; Zuchero et al., 2015).

Neural Wiskott-Aldrich syndrome protein (N-Wasp) is a nucleation-promoting factor that drives the generation of branched actin filaments (Alekhina et al., 2017). It regulates cortical actin filament reorganization in response to extracellular stimuli by linking between small GTPases (i.e., Rac and Cdc42) and actin polymerization through the regulation of the Arp2/3 complex (Takenawa and Miki, 2001). N-Wasp and Wasp family verprolin homologous protein-1 (WAVE1) are required for myelination in the PNS and CNS, respectively, and regulate oligodendrocyte differentiation (Kim et al., 2006; Bacon et al., 2007; Jin et al., 2011; Novak et al., 2011). N-Wasp is expressed by both oligodendrocytes and myelinating Schwann cells (Tsuchiya et al., 2006; Novak et al., 2011; Zhang et al., 2014; Marques et al., 2016). It plays a crucial role in Schwann cell membrane wrapping and in longitudinal extension of the myelin unit in the PNS, most likely via regulation of the actin cytoskeleton (Jin et al., 2011; Novak et al., 2011). Schwann cells from N-Wasp-mutant mice formed less radial lamellipodia and shorter axial processes that lacked defined F-actin-rich cones (Jin et al., 2011). In the absence of N-Wasp, Schwann cells properly sort and ensheath the axons, but were not capable of proceeding with myelin wrapping (Jin et al., 2011; Novak et al., 2011). In the CNS, N-Wasp was detected with components of the Arp $2 / 3$ complex in newly formed oligodendrocytes and in purified myelin fractions (Bacon et al., 2007). Moreover, pharmacological inhibition of $\mathrm{N}$-Wasp prevented process extension and caused filopodium retraction in cultured oligodendrocyte precursor cells. Overall, these data suggest that cellular process extension by oligodendrocyte precursor cells is regulated by N-Wasp and Arp2/3-driven actin polymerization. Here we report that genetic deletion of $\mathrm{N}$-Wasp in oligodendrocytes results in hypomyelination, diverse myelin abnormalities, including outfoldings that enwrap neuronal cell bodies, as well as myelin and axonal degeneration.

\section{Materials and Methods}

Mice. Generation of $N$-Wasp ${ }^{f l x f f l x}$ (Cotta-de-Almeida et al., 2007) and Cnp-Cre (Lappe-Siefke et al., 2003) mice were previously described and was always kept as heterozygous. Cnp-Cre/N-Wasp $p^{f l x / f l x}$ mice (i.e., homozygous for N-Wasp) were obtained by a conventional breeding scheme. Genotypes were determined by performing PCR on genomic DNA extracted from mice tails. Both male and female animals were used in the study, with no detectable difference in myelin morphology. Rotarod motor test was performed using an accelerating rotarod as previously described (Novak et al., 2011). All experiments were performed in compliance with the relevant laws and institutional guidelines and were approved by the Weizmann Institute's Animal Care and Use Committee.

$R T-P C R$. Total RNA was isolated from optic nerves as described previously (Novak et al., 2011). PCR was performed using N-Wasp (5'GTGCAGTTGTATGCAGCAGATCG-3' and $5^{\prime}$-GGTGTGGGAGAT GTTGTTG-3') or the previously described actin-specific primers (Novak et al., 2011).

Histochemistry and immunofluorescence. Mice were anesthetized and perfused with 2.5\% PFA. Brains were isolated and postfixed on ice for $30 \mathrm{~min}$, and Luxol Fast Blue (LFB) staining was performed as described previously (Elazar et al., 2019b). For immunofluorescence, sections were washed with PBS, blocked, and permeabilized in PBS containing $5 \%$ normal goat serum, $0.5 \%$ Triton $\mathrm{X}-100$ for $1 \mathrm{~h}$ at room temperature. Samples were incubated overnight at $4^{\circ} \mathrm{C}$ with primary antibodies to MBP (1:300; MAB386, Chemicon) diluted in blocking solution with $0.1 \%$ Triton X-100, washed with PBS, incubated for $45 \mathrm{~min}$ at room temperature with secondary antibodies coupled to Dylight 488 (from Jackson ImmunoResearch Laboratories), and then washed with PBS and mounted with Fluoromount-G. Images were acquired using a Panoramic digital slide scanner (3DHISTECH). For image analysis, images were taken in equivalent spatial distribution from all slides.

Western blot analysis. Mouse optic nerves were lysed as described previously (Elazar et al., 2019b). Membranes were blotted with antibodies to N-Wasp (1:500; HPA005750, Sigma Millipore) and $\beta$-tubulin (1:1000; T7816, Sigma Millipore), reacted with HRP-conjugated secondary antibodies, developed by ECL, and imaged on Bio-Rad ChemiDoc.

$E M$. Mice were anaesthetized and perfused with a fixative containing 4\% PFA, $2.5 \%$ glutaraldehyde in $0.1 \mathrm{~m}$ cacodylate buffer, $\mathrm{pH}$ 7.4. Brains, optic nerves, and spinal cords were isolated and incubated in the fixative overnight at room temperature and processed as previously described (Elazar et al., 2019a). For sciatic nerve teasing, mice were killed, and their sciatic nerves exposed and fixed by continuous dripping of fresh fixative containing $4 \%$ PFA, $2.5 \%$ glutaraldehyde in $0.1 \mathrm{~m}$ cacodylate buffer, $\mathrm{pH}$ 7.4, for $25 \mathrm{~min}$. Postfixation handling and processing were conducted as previously described (Amor et al., 2017). Samples were examined using a Tecnai Spirit or T12 transmission electron microscope, equipped with a FEI Eagle camera or a Gatan ES500W Erlangshen camera, respectively. EM micrographs were analyzed using computer-assisted Image J (National Institutes of Health) analysis software.

Statistical analysis. Myelin abnormalities and degenerated profiles were calculated by counting $>800$ myelinated axons ( 3 mice per genotype). The number of myelinated axons was calculated per $\mathrm{mm}^{2}$, presented as percent from the average of 3 animals from each genotype (normalized to WT mice). The percent of abnormal profiles was calculated from the average percentage of 3 animals from each genotype. The g-ratio was calculated by dividing the measured inner axonal diameter to the measured total outer axonal diameter from $>200$ axons ( 3 mice per genotype). This was done in three steps: In the first step, the inner axons were automatically detected by a dedicated Fiji (Schindelin et al., 2012) macro that enhanced the myelin using mean filter followed by bandpass filter, applied fix threshold to segment inner axons parts, and cleaned them by filling small holes and discarding small and noncircular objects. In the second step, outer profiles were manually drawn around selected $(>200)$ axons and saved. The third part used another Fiji macro to match inner and outer profiles, and to calculate their area, effective diameter, and the g-ratio. The Fiji macro as well as instructions for manual drawing are available at: https://github.com/WIS-MICCCellObservatory/SemiManual_Myelin_Profiles. Data are mean \pm SEM. Statistical analyses were performed using student's two-tailed $t$ test.

\section{Results}

\section{Genetic deletion of N-Wasp in oligodendrocytes results in hypomyelination}

We have previously found that, while the presence of N-Wasp in Schwann cells is not required for axonal sorting and initial axonal ensheathment, it is entirely essential for membrane wrapping and the formation of PNS myelin (Novak et al., 2011). In order to examine the function of N-Wasp in CNS myelination, we have generated mice lacking N-Wasp in oligodendrocytes by using a conditional floxed allele of N-Wasp, in which the second coding exon was flanked by loxP sites $\left(N-W_{a s p} p^{f l x / f l x}\right)$ (Cottade-Almeida et al., 2007). Oligodendrocyte-specific deletion of $\mathrm{N}$-Wasp was obtained by crossing $N$-Wasp $p^{f l x f l x}$ mice with CnpCre mice, in which Cre is active in premyelinating oligodendrocytes from embryonic day 12 (Lappe-Siefke et al., 2003). To validate the ablation of N-Wasp in Cnp-Cre/N-Wasp ${ }^{f l x / f l x}$ mice, we performed RT-PCR analysis on mRNA isolated from optic nerves of 2-month-old $N$-Wasp $p^{f l x / f l x}$ (referred to WT throughout the manuscript) and Cnp-Cre/N-Wasp $p^{f l x / f l x}$ mice. This analysis 
A

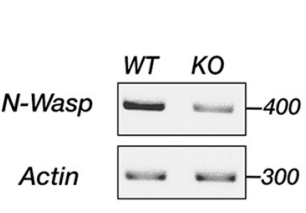

B
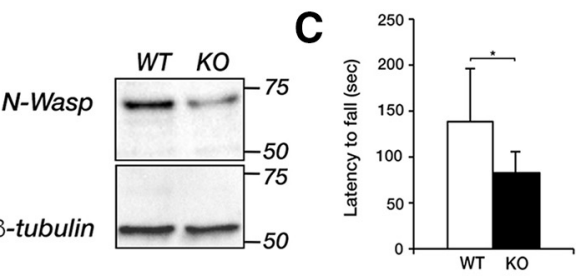

WT
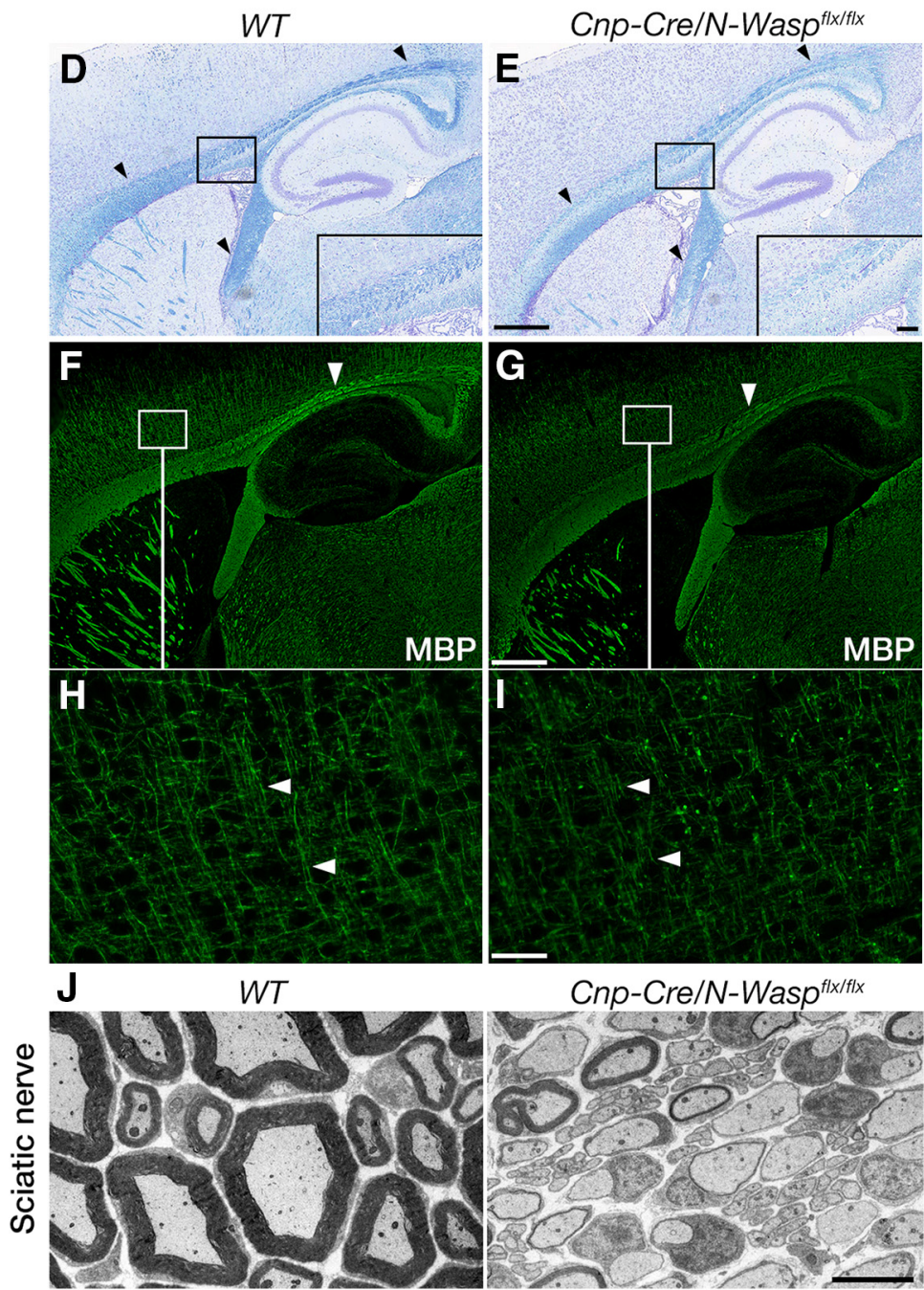

Cnp-Cre/N-Wasp $p^{f l x / f l x}$

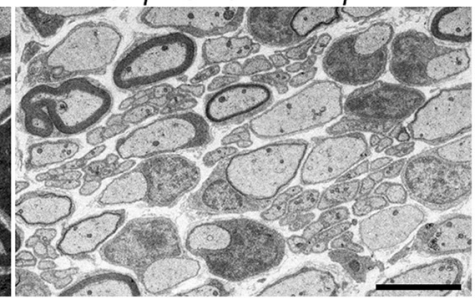

Figure 1. Absence of $\mathrm{N}$-Wasp in oligodendrocytes results in hypomyelination. $\boldsymbol{A}, \mathrm{RT}-\mathrm{PCR}$ analysis of mRNA isolated from optic nerves at 2 months from Cnp-Cre/N-Wasp ${ }^{f(x) f f x}$ mutant and from N-Wasp ${ }^{f x / f f x}$ (WT) mice. Amplification of N-Wasp and actin was performed using the relevant primers, and products of expected sizes were obtained. $\boldsymbol{B}$, WB analysis of optic nerves isolated at 2 months from Cnp-Cre/N-Wasp ${ }^{f x / f l x}$ mutant and from N-Wasp flxfflx (WT) mice using antibodies to N-Wasp and $\beta$-tubulin. C, Rotarod test performed with 3-month-old Cnp-Cre/N-Wasp ${ }^{f(x / f l x}$ mutant and from N-Wasp ${ }^{f(x / f x}$ (WT) mice. The mutant mice had a shorter latency to fall than their littermate control. Error bars indicate SD of $n>5$ mice for each genotype $\left({ }^{*} p<0.05\right)$. D-I, Sagittal sections of brains from 2-month-old $N$-Wasp ${ }^{f(x / x}(\mathrm{WT} ; \boldsymbol{D}, \boldsymbol{F}, \boldsymbol{H})$ and $C n p$-Cre/N-Wasp ${ }^{f x / f l x}(\boldsymbol{E}, \boldsymbol{G}, \boldsymbol{I})$ mice stained with LFB and crysel violet $(\boldsymbol{D}, \boldsymbol{E})$, or immunolabeled using antibodies to MBP $(\boldsymbol{F}-\boldsymbol{I})$. Hypomyelination is detected in the mutant corpus callosum and the fimbria ( $\boldsymbol{D}-\boldsymbol{G}$, arrowheads). $\boldsymbol{D}, \boldsymbol{E}$, Insets, High-magnification image of the framed area in the corpus callosum. $\boldsymbol{H}, \boldsymbol{I}$, High-magnification images of the framed regions in $\boldsymbol{F}$ and $\boldsymbol{G}$ showing a decrease in MBP immunoreactivity in the absence of N-Wasp (arrowheads). J, Cnp-Cre/N-Wasp flxfflx mice lack myelin profiles in the PNS. EM images of sciatic nerve cross sections from 2-month-old $N$-Wasp ${ }^{f l}$ fflx $(\mathrm{WT})$ and $\mathrm{Cnp}$-Cre/N-Wasp ${ }^{f x / f l x}$ mutant mice. In mutant nerves, most Schwann cells were arrested at the promyelinating stage, similarly to our DHH-Cre/N-Wasp ${ }^{f l x f l x}$ mutant nerves (Novak et al., 2011). Scale bars: $\boldsymbol{D}-\mathbf{G}, 500 \mu \mathrm{m}$; Inset, $100 \mu \mathrm{m} ; \boldsymbol{H}, \mathbf{I}, 50 \mu \mathrm{m} ; \boldsymbol{J}, 5 \mu \mathrm{m}$.

revealed a significant decrease of $\mathrm{N}$-Wasp transcript in the mutant (Fig. 1A). Similarly, Western blot analysis of optic nerves revealed a clear decrease in the amount of N-Wasp protein in optic nerves of Cnp-Cre/N-Wasp $p^{f l x / f l x}$ compared with control mice (Fig. 1B). Residual mRNA and protein levels of N-Wasp still detected in Cnp-Cre/N-Wasp $p^{f l x / f l x}$ optic nerves were likely due to its expression in other cell types, such as neurons and astrocytes. Cnp-Cre/ $N$-Wasp $p^{f l f f l x}$ mice exhibited a severe tremor and a hindlimb paralysis, and had shorter latency to fall from a rotarod compared with WT mice (Fig. 1C). These motor impairments resembled the phenotype of $\mathrm{DHH}$-Cre/N-Wasp $\mathrm{p}^{f l x / f l x}$ mice (Novak et al., 2011), and are likely attributed the expression of Cnp-Cre in myelinating Schwann cells. In agreement, EM analysis revealed that, similar to $\mathrm{DHH}-\mathrm{Cre} / \mathrm{N}-\mathrm{Wasp} \mathrm{flx}^{f f l x}$ animals, sciatic nerves of adult Cnp-Cre/N-Wasp flx/flx mice almost completely lacked myelin profiles (Fig. 1J).

In order to evaluate the contribution of N-Wasp to CNS myelin, we first examined sagittal brain sections prepared from 2-month-old mutant mice stained with LFB (Kluver and Barrera, 1953). While the overall brain morphology and the formation of white matter tracks were similar between WT and mutant brains, the latter clearly exhibited hypomyelination in several brain regions, including the corpus callosum and the hippocampal fimbria (Fig. 1D,E). Similarly, we noted a decrease in MBP immunoreactivity throughout the brain (Fig. $1 F-I$ ). We next examined optic nerves from 1-month-old WT and Cnp-Cre/N-Wasp $p^{f l x / f l x}$ mice by EM. As depicted in Figure $2 A, B$, Cnp$\mathrm{Cre} / \mathrm{N}$-Wasp $p^{f l x / f l x}$ mice displayed pronounced hypomyelination in the optic nerve. These mice exhibited a lower number of myelinated axons (Fig. 2C), thinner myelin profiles (i.e., higher g-ratio; Fig. $2 D, E)$, as well as an increase in the number of abnormal profiles (Fig. 2F; and detailed below) compared with their littermate control. Hypomyelination, increase in g-ratio, and a fourfold increase in the occurrence of additional myelin abnormalities were also detected in Cnp$\mathrm{Cre} / \mathrm{N}-\mathrm{Wasp} \mathrm{flx}^{f l f x}$ mice at 4 months of age (Fig. 2G-N).

\section{Mice lacking N-Wasp in \\ oligodendrocytes exhibit diverse myelin abnormalities}

EM analysis of different brain areas, including the corpus callosum, optic nerve, and the cerebellum, revealed that the most pronounced abnormality resulted from the absence of N-Wasp in oligodendrocytes was the formation of long myelin outfolds (Fig. 3A-F). We noted the presence of long myelin outfolds that extended throughout the neuropil (Fig. $3 A$ ), as well as myelin outfolds that surrounded either nonmyelinated (Fig. 3B) or myelinated (Fig. 3C) axons. The association between myelin outfolds and preexisting myelin sheath often resulted in the 
formation of a pseudo-multimyelin configuration around the axon (Fig. 3D). In these structures, the outer membrane of the myelin outfold contact the outer membrane of exiting myelin (i.e., reverse orientation), and the two inner membranes of the outfolding faced each other (Fig. 3D,M,N). Notably, these are likely distinct from the multimyelin configuration (Fig. 3L) formed by membrane slippage as a result of aberrant axoglial adhesion (Djannatian et al., 2019; Elazar et al., 2019a). In the cerebellum, we observed long myelin outfolds extending from the axon and either partially or completely surrounding neuronal somata in the granular layer (Fig. 3E,F). Throughout the brain and spinal cord, we detected pseudo-multimyelin profiles that were often accompanied by myelin deterioration (emerging cytoplasmic spaces between myelin sheaths), axonal detachment, and degeneration (Fig. 3G-J). We did not detect axonal pathology in nonmyelinated fibers, suggesting that the axonal pathology observed in Cnp-Cre/ $N$-Was $p^{f l x / f l x}$ mice is secondary to myelin disintegration. In support of this conclusion, the appearance of a degenerated axon was frequently associated with the presence of abnormal and degenerated myelin sheath around the axons.

\section{Myelin abnormalities occur already at early developmental stage}

We next examined whether the myelin pathology observed in the absence of $\mathrm{N}$-Wasp occurred during the period of active developmental myelination in the optic nerve (Rasband et al., 1999). We performed EM analysis of P10 (Fig. 4A) and P15 (Fig. 4B) optic nerves isolated from WT and Cnp-Cre/N-Wasp $p^{f l x / f l x}$ mice to examine the number of myelinated axons, as well as myelin abnormalities. While there was no statistically significant difference in the number of myelinated profiles between the genotypes at P10 (Fig. 4C), the percentage of myelinated axons was significantly lower in the mutant than in WT optic nerves at P15 (Fig. 4E). Nevertheless, the number of myelin outfolds detected in optic nerves of Cnp-Cre/N-Wasp flx/flx mutant mice was significantly higher than their age-matched control littermates at both P10 (Fig. 4D) and p15 (Fig. 4F). Notably, we detected long projecting myelin outfolds (Fig. 4A, right), as well as multimyelin and degenerated profiles (Fig. $4 A$, middle) in the mutant optic nerve already at P10, indicating that the absence of N-Wasp in oligodendrocytes leads to dysregulation of CNS myelination. In addition, while we detected intact axons that were surrounded by abnormal myelin, we rarely detected degenerated axons enwrapped by normal myelin, further supporting the notion that axonal degeneration in these mice is secondary to myelin impairment.

\section{Absence of N-Wasp in oligodendrocytes leads to myelin abnormalities in multiple CNS areas}

It was previously reported that deletion of WAVE1, which belongs to the same protein family of N-Wasp, resulted in hypomyelination only in certain regions in the CNS (Kim et al., 2006). To further examine whether deletion of N-Wasp also affects myelination in a regional manner, we performed EM analysis of the corpus callosum and spinal cord of WT and Cnp$\mathrm{Cre} / \mathrm{N}$-Wasp ${ }^{f l x / f l x}$ mice. We detected severe myelin abnormalities, including the formation of outfolds, redundant myelin, and degeneration in both the corpus callosum (Fig. 5A,B) and spinal cord (Fig. 5C,D). Furthermore, in the spinal cord, myelin pathology and degeneration (Fig. 5E,F) were progressive and increased from 1- to 4-month-old animals (Fig. 5G). Together, our results show that, in contrast to the ablation of N-Wasp in Schwann cells, N-Wasp-deficient oligodendrocytes produce abundant 

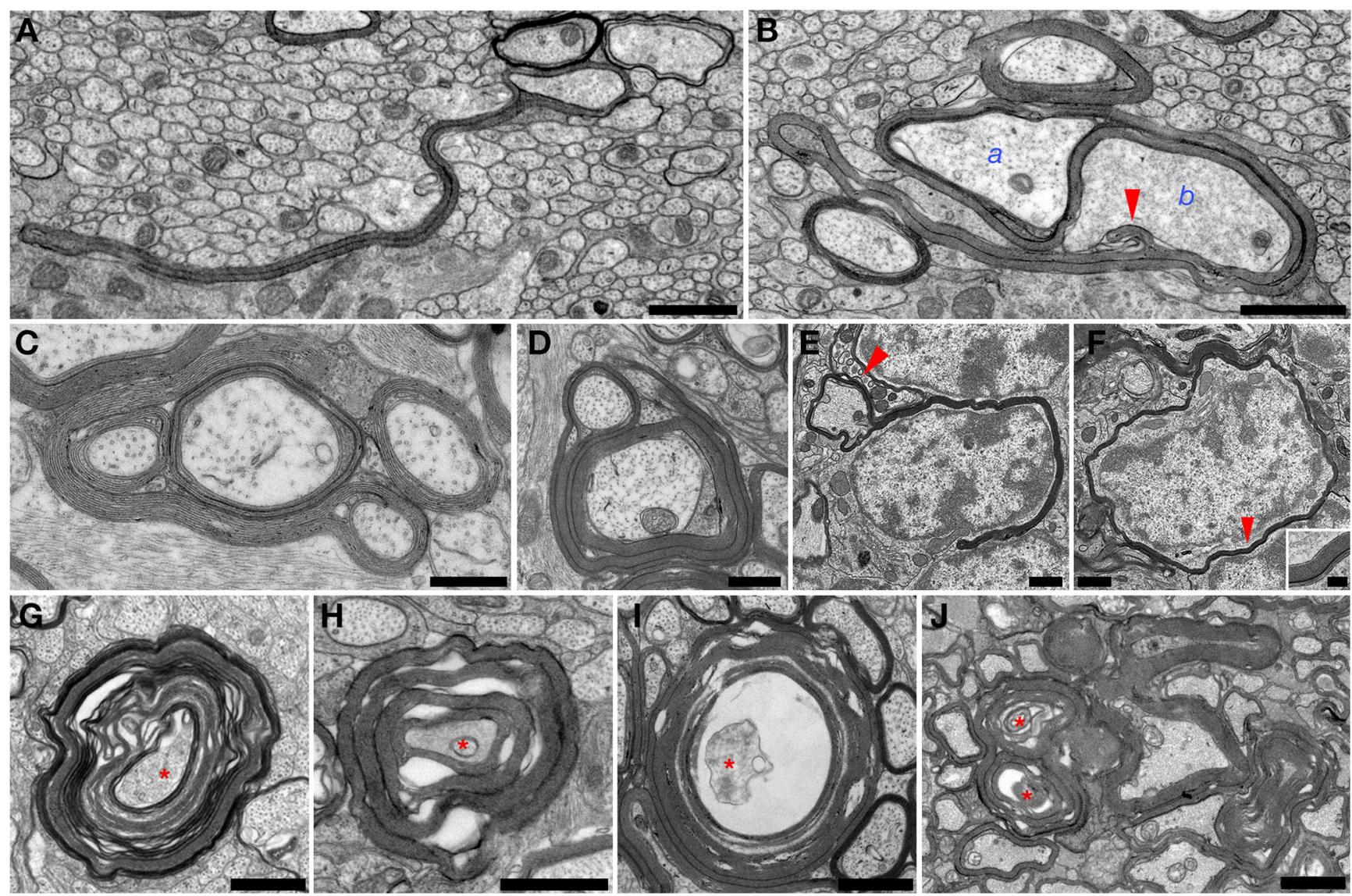

K

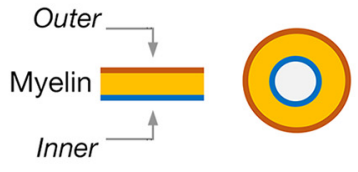

Normal Myelin
$\mathbf{L}$

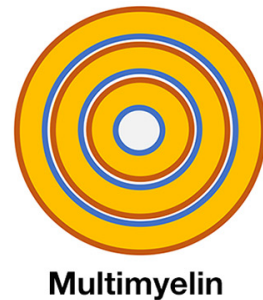

M

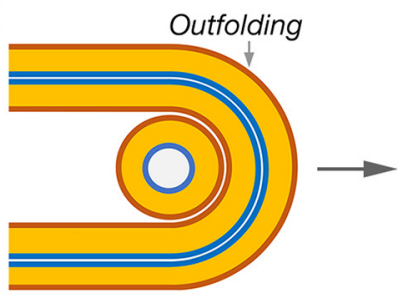

Pseudo-Multimyelin

Figure 3. Cnp-Cre/N-Wasp ${ }^{f x / f x}$ mice exhibit severe myelin abnormalities. $A, B, E M$ images of Cnp-Cre/N-Wasp ${ }^{f(x) \text { fx }}$ corpus callosum at P15. The long extending myelin outfolds originated from one axon (labeled a in $\boldsymbol{B}$ ) surrounds a nonmyelinated axon (b), and extends an additional outfold (arrowhead) that contact this axon. $\boldsymbol{C}, \boldsymbol{D}$, High-magnification EM images of optic nerve cross sections obtained from 1-month-old Cnp-Cre/N-Wasp ${ }^{f x / f l x}$ mutant mice, showing long myelin outfoldings. Myelin outfolds cover other myelinated axons. $E, F$, Presence of oligodendrocyte myelin around neuronal cell bodies. EM images of the cerebellum of 4-month-old Cnp-Cre/ $N$-Wasp ${ }^{f x / f x}$ mutant mice. The presence of myelin outfolds that either partially $(\boldsymbol{E})$ or completely $(\boldsymbol{F})$ surrounding neuronal cell bodies. $\boldsymbol{E}$, Arrow indicates the presence of a nearby myelinated axon. High magnification of area indicated by arrowhead in $\boldsymbol{F}$ showing multiple myelin layers around the cell body. G-I, High-magnification EM images of optic nerve cross sections obtained from P10 (G), P15 (H), and P30 (I) Cnp-Cre/N-Wasp ${ }^{f(x / f x}$ mutant mice showing different configurations of multimyelinated axons undergoing degeneration and axon (red asterisk) detachment. J, EM image of optic nerve cross sections obtained from 4-month-old Cnp-Cre/N-Wasp ${ }^{f / x f f x}$ mutant mice showing multiple profiles of focal hypermyelination and degeneration (red asterisk). $\boldsymbol{K}-\boldsymbol{N}$, Schematic model showing normal myelin (K), multimyelin configuration resulting from aberrant adhesion $(\boldsymbol{L})$, and pseudo-multimyelin configuration formed by wrapping of a myelin outfolding around myelinated axon $(\boldsymbol{M}, \boldsymbol{M})$. $\boldsymbol{K}$, The myelin sheath (Myelin) and the location of the most inner and outer myelin membranes. Scale bars: $\boldsymbol{A}, \boldsymbol{B}, \boldsymbol{D}-\boldsymbol{I}, 1 \mu \mathrm{m} ; \boldsymbol{C}, 0.5 \mu \mathrm{m} ; \boldsymbol{J}, 2 \mu \mathrm{m}$.

myelin. However, experimental deletion of N-Wasp in oligodendrocytes results in the formation of abnormal myelin membrane extensions and degeneration of myelinated axons, indicating that it is required for the normal CNS myelination.

\section{Discussion}

During CNS myelination, oligodendrocytes extend cellular processes that contact axons and form myelin internodes by continually wrapping their membrane around them (Czopka et al., 2013; Snaidero et al., 2014; Stadelmann et al., 2019). These extensive morphological changes are tightly regulated by dynamic reorganization of the cortical actin cytoskeleton (Nawaz et al., 2015;
Zuchero et al., 2015; Seixas et al., 2019; Brown and Macklin, 2020; Thomason et al., 2020). N-Wasp affects actin filament polymerization by regulating the nucleation activity of Arp2/3. We found that genetic ablation of N-Wasp in oligodendrocytes results in hypomyelination, extensive formation of myelin outfoldings, and degeneration of myelinated axons throughout the brain and spinal cord, demonstrating that $\mathrm{N}$-Wasp plays a critical role in the formation of normal CNS myelin. Our data support previous studies indicating that the regulation of actin filament dynamics is critical for both the initial extension of cellular process during axonal selection, as well as for membrane ensheathment and wrapping during myelination (Nawaz et al., 
2015; Zuchero et al., 2015; Azevedo et al., 2018). The observation that the absence of $\mathrm{N}$-Wasp in oligodendrocytes leads to hypomyelination (as reflected by a lower number of myelinated axons and thinner myelin sheath), is also in line with in vitro observations showing that chemical inhibition of N-Wasp in cultured oligodendrocytes by wiskostatin, which prevents activation of the Arp2/3 complex, results in the inhibition of process extension (Bacon et al., 2007). Studies on actin dynamics in developing oligodendrocytes and myelination suggest a role for Arp2/3-dependent actin polymerization during the initial stages of axonal contact and ensheathment, following by actin filament disassembly, which decreases membrane surface tension and promotes radial movement of the membrane during myelin wrapping (Nawaz et al., 2015; Zuchero et al., 2015). In agreement with a spatial role of actin polymerization during the early phase of myelination, N-Wasp along with Arp2/3 complex components were both noted at the edges of cellular extensions in cultured oligodendrocytes (Bacon et al., 2007). In addition, the expression of $\mathrm{N}$-Wasp is higher in premyelinating and newly formed oligodendrocytes than in myelinating oligodendrocytes (Zhang et al., 2014; Seixas et al., 2019). Our findings also support a role for NWasp during myelin membrane wrapping, either by inducing actin assembly needed for continues actin turnover at the edge of the inner lip (Nawaz et al., 2015), or by contributing to the cortical actin scaffold required for a local actin depolymerization-dependent progression of the inner lip (Zuchero et al., 2015). The remarkable similarity between Cnp-Cre/N-Wasp fla/flx and Cnp-Cre/ArpC fllx/flx mice (Zuchero et al., 2015) strongly suggests that the role $\mathrm{N}$-Wasp plays in myelination is mediated by actin polymerization via the Arp $2 / 3$ complex.

One of the most prominent abnormalities detected in CnpCre/N-Wasp flx $/ f l x$ mice is the formation of myelin outfolds, defined as inappropriate growth of myelin membrane extensions away from the axons. These were observed in the optic nerve, corpus callosum, and spinal cord, and often resulted in the formation of what we term pseudo-multimyelin configuration, in which the outer membrane of the myelin outfold contacted the outer membrane of exiting myelin (i.e., reverse orientation), and the two inner membranes of the outfold were squeezed and faced each other (Fig. $3 M, N)$. Notably, these are distinct from the multimyelin configuration formed by membrane slippage as a result of aberrant axoglial adhesion (Djannatian et al., 2019; Elazar et al., 2019a). In addition to pseudo-multimyelin, we also detected myelin outfolds around nonmyelinated axons, as well as around neuronal cell bodies, suggesting that their growth is mainly determined by the space constraints within the local environment. The presence of extensive myelin outfoldings detected in the absence of N-Wasp in oligodendrocytes indicates that actin polymerization is required to control membrane growth during myelination. This notion is reinforced by the observation that myelin outfoldings are prominent after genetic deletion of the essential subunit of the Arp2/3 complex ArpC3 (Zuchero et al., 2015). Furthermore, similar myelin outfoldings characterized by abnormal accumulation of cytoplasm in the inner tongue of the myelin sheath were detected after oligodendrocyte-specific ablation of Rho GTPases Cdc42 (Thurnherr et al., 2006), which is a known activator of N-Wasp (Rohatgi et al., 2000). Collectively, our data suggest that membrane growth and correct myelin sheath formation are regulated by actin polymerization via the Cdc42-N-Wasp-Arp2/3 axis. In addition, the misguided movement of the oligodendrocyte leading edge away from the axon after ablation of N-Wasp could result from disrupted axoglial adhesion (Djannatian et al., 2019; Elazar et al., 2019a). N-Wasp is known to regulate cell adhesion (Misra et al., 2007), and the mobility of cell surface receptors (Rey-Suarez et al., 2020), raising the possibility that it may be involved in regulating oligodendrocyte-axon contact. Genetic deletion of N-Wasp in Schwann cells leads to reduced expression of myelin-associated glycoprotein (Jin et al., 2011), an adhesion axoglial molecule that was recently found to cooperate with other axoglial adhesion systems in targeting the inner tongue of oligodendrocytes during myelination (Garcia and Zuchero, 2019). Accordingly, the absence of $\mathrm{N}$-Wasp in oligodendrocytes may not only impair the assembly of actin filaments, but also affect the adherence of the protruding 
A

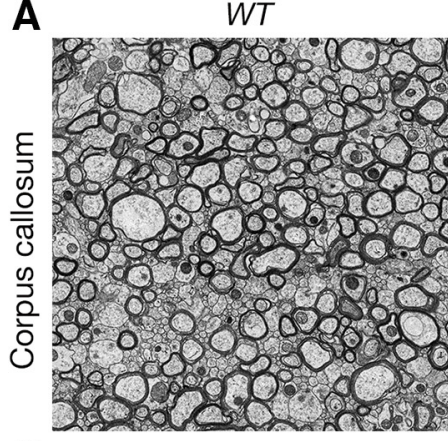

C

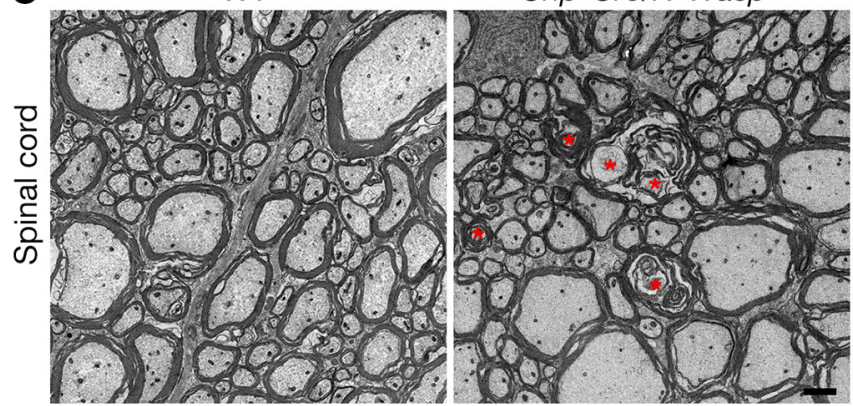

E

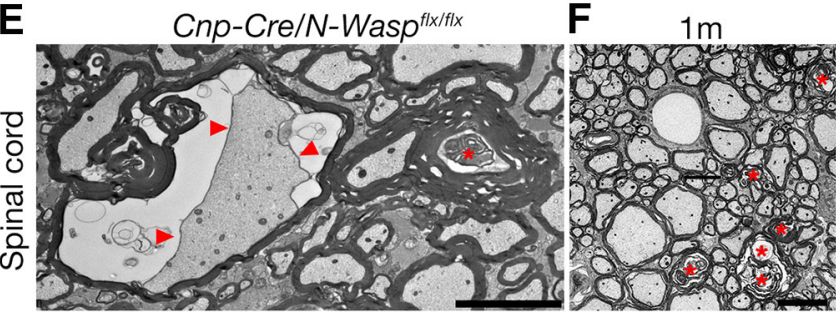

Cnp-Cre/N-Wasp ${ }^{f l x / f l x}$
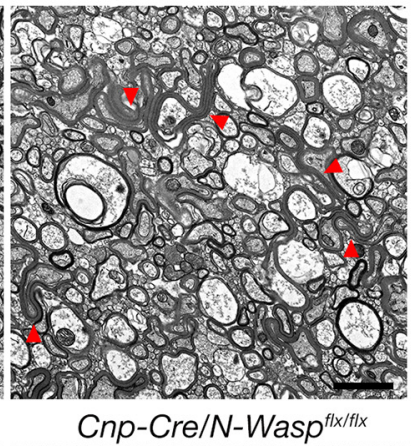

$D$
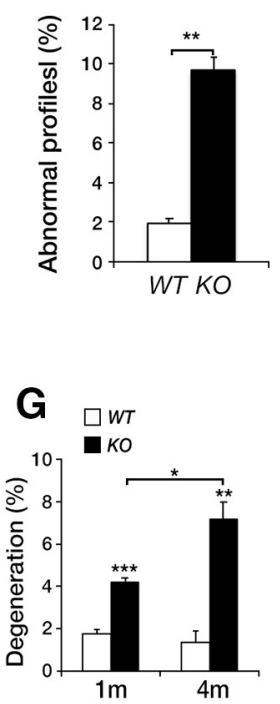

Figure 5. Cnp-Cre/N-Wasp ${ }^{f x / f f x}$ mice display myelin impairments and axonal degeneration in different CNS tissues. A, C, EM images of corpus callosum (A) and spinal cord (C) from N-Wasp ${ }^{f f / f x}(\mathrm{WT})$ and $\left(n p-C r e / N-W a s p^{f x / f x}\right.$ mutant mice (KO). Red arrowheads indicate abnormal myelin outfoldings. Red asterisks indicate degenerated profiles at different stages. $\boldsymbol{B}, \boldsymbol{D}$, Graphs representing percentage of abnormal myelin profiles in both genotypes. Three to five random FOVs were used from 3 mice for each genotype. ${ }^{* *} p<0.01$. Error bars indicate mean \pm SEM. $E, F$, EM images of spinal cord cross sections from 4-month-old $(\boldsymbol{E})$ and 1-month-old $(\boldsymbol{F})\left(\mathrm{Cnp}\right.$-Cre/N-Wasp ${ }^{f f_{\mathrm{f}} / \mathrm{x}}$ mutant mice $(\mathrm{K} 0)$. Red asterisks indicate degenerated profiles at different stages. $\boldsymbol{E}$, Arrowheads indicate detachment of the axon from the myelin sheath. $\boldsymbol{G}$, Quantification of degenerated profiles (myelin sheaths and axons) detected in $N$-Wasp $p^{f x / f x}$ (WT) and $\left(n p\right.$-Cre/N-Wasp ${ }^{f x / f x}$ mutant mice (KO). Results shown as percentage of degenerated profiles of all myelinated axons at different ages. Three to five random FOVs were used from 3 mice for each genotype. ${ }^{* * *} p<0.0001 .{ }^{* *} p<0.01$. ${ }^{*} p<0.05$. Error bars indicate mean \pm SEM. Scale bars: $A, C, F, 2 \mu \mathrm{m} ; \boldsymbol{E}, 10 \mu \mathrm{m}$.

lead to oligodendrocyte-axon decoupling and axonal degeneration. Another intriguing possibility to consider is that contact between the outer membranes of the outfolding and the myelin ensheathing the axon induces a myelin deterioration signal. Such a possibility is supported by observation demonstrating that the spatial segregation of myelin segments in the cortex is mediated by contact-dependent inhibitory signals between oligodendrocytes (Chong et al., 2012). While the exact underlying mechanisms are yet to be explored, our results emphasize the role actin dynamic has in proper myelin wrapping and the control of axonal integrity.

A surprising observation of this study is that the ablation of N-Wasp resulted in two distinct phenotypes in the CNS and PNS. In the PNS, N-Wasp is not required for axonal sorting, a process during which membrane extensions of Schwann cells select larger axons for myelination during development, nor for the initial ensheathment of axons, but is totally necessary for continuous membrane wrapping and the formation of myelin segments (Jin et al., 2011; Novak et al., 2011). In contrast, in the CNS, N-Wasp affects process extension by oligodendrocytes (Bacon et al., 2007), and hence axonal ensheathment and the number of segments formed. In addition, in the absence of N-Wasp in the CNS, membrane wrapping does accrue but often resulted in focal hypermyelination as evident by the formation of aberrant myelin outfolds. It is interesting to note that, in terms of actin dynamics, the process of axonal sorting by Schwann cells could actually be considered equivalent to oligodendrocytes branching and their initial ensheath-

inner tongue, further leading to the formation of redundant myelin outfolds.

In addition to impaired myelination in brains and spinal cords of Cnp-Cre/N-Wasp $p^{f l x f l x}$ mice, we found pronounced myelin sheath and axonal degeneration, which were secondary to myelin damage. Degenerated axons were typically accompanied by focal hypermyelination attributed to outfolds that surrounded myelinated axons. The association between axonal degeneration and multimyelin profiles is particularly intriguing as it raises the possibility that degeneration is caused by the instability of such abnormal structures. Notably, no axonal pathology was observed in normal nonmyelinated fibers, suggesting that axonal pathology observed in Cnp-Cre/N-Wasp $p^{f l x f l x}$ mice is oligodendrocytedependent. Oligodendrocytes have been shown to provide supportive signals that are necessary for axonal integrity (Nave and Werner, 2014). The presence of outfoldings around myelinating oligodendrocytes would separate them from the interstitial fluid, which provides a direct medium for substance exchange between the cell and the extracellular space. This would interfere with their own physiological requirements, and may ment of axons (Feltri et al., 2016). Hence, supported by studies of several other regulators of actin dynamics, such as Myosin II (Wang et al., 2008), Dynamin 2 (Gerber et al., 2019), and Dystonin I (Kornfeld et al., 2016), our findings indicate the existence of fundamental differences in the role actin reorganization plays during CNS and PNS myelination. Alternatively, the relative limited effect N-Wasp ablation has on CNS compared with PNS myelination could result from a possible compensatory mechanism by other actin nucleation-promoting factors of the Arp2/3 complex. N-Wasp belongs to the WASP protein family (i.e., WASP, WAVE, WASH, WHAMM, and JMY), of which several members are expressed in the oligodendrocyte lineage (Cahoy et al., 2008; Zhang et al., 2014; Marques et al., 2016). In line with this possibility, knockdown of JMY (junction-mediating and regulatory protein) in cultured oligodendrocytes impaired the formation of cellular protrusion and branching, and resulted in a reduced ability to contact axons and form myelin internodes when cocultured with neurons (Azevedo et al., 2018). Another candidate protein that may compensate for the 
loss of N-Wasp is WAVE1, which like JMY and N-Wasp (Bacon et al., 2007), also regulates process outgrowth and lamellipodia formation in cultured oligodendrocytes (Kim et al., 2006). Furthermore, a general deletion of WAVE1 in mice results in a regional-specific hypomyelination (Kim et al., 2006), which is somewhat complimentary to the one we observed in $\mathrm{Cnp}-\mathrm{Cre} / \mathrm{N}$ Wasp $^{f l x / f l x}$ mutant mice. Whether WAVE1 provides compensatory function in the absence of $\mathrm{N}$-Wasp will require the use of mice lacking both genes specifically in oligodendrocytes.

\section{References}

Alekhina O, Burstein E, Billadeau DD (2017) Cellular functions of WASP family proteins at a glance. J Cell Sci 130:2235-2241.

Almeida RG, Lyons DA (2014) On the resemblance of synapse formation and CNS myelination. Neuroscience 276:98-108.

Amor V, Zhang C, Vainshtein A, Zhang A, Zollinger DR, Eshed-Eisenbach Y, Brophy PJ, Rasband MN, Peles E (2017) The paranodal cytoskeleton clusters $\mathrm{Na}(+)$ channels at nodes of Ranvier. Elife 6:e21392.

Azevedo MM, Domingues HS, Cordelieres FP, Sampaio P, Seixas AI, Relvas JB (2018) Jmy regulates oligodendrocyte differentiation via modulation of actin cytoskeleton dynamics. Glia 66:1826-1844.

Bacon C, Lakics V, Machesky L, Rumsby M (2007) N-WASP regulates extension of filopodia and processes by oligodendrocyte progenitors, oligodendrocytes, and Schwann cells: implications for axon ensheathment at myelination. Glia 55:844-858.

Bauer NG, Richter-Landsberg C, Ffrench-Constant C (2009) Role of the oligodendroglial cytoskeleton in differentiation and myelination. Glia 57:1691-1705.

Brown TL, Macklin WB (2020) The actin cytoskeleton in myelinating cells. Neurochem Res 45:684-693.

Cahoy JD, Emery B, Kaushal A, Foo LC, Zamanian JL, Christopherson KS, Xing Y, Lubischer JL, Krieg PA, Krupenko SA, Thompson WJ, Barres BA (2008) A transcriptome database for astrocytes, neurons, and oligodendrocytes: a new resource for understanding brain development and function. J Neurosci 28:264-278.

Chong SY, Rosenberg SS, Fancy SP, Zhao C, Shen YA, Hahn AT, McGee AW, Xu X, Zheng B, Zhang LI, Rowitch DH, Franklin RJ, Lu QR, Chan JR (2012) Neurite outgrowth inhibitor Nogo-A establishes spatial segregation and extent of oligodendrocyte myelination. Proc Natl Acad Sci USA 109:1299-1304.

Cohen CC, Popovic MA, Klooster J, Weil MT, Mobius W, Nave KA, Kole $\mathrm{MH}$ (2020) Saltatory conduction along myelinated axons involves a periaxonal nanocircuit. Cell 180:311-322.e15.

Cotta-de-Almeida V, Westerberg L, Maillard MH, Onaldi D, Wachtel H, Meelu P, Chung UI, Xavier R, Alt FW, Snapper SB (2007) Wiskott Aldrich syndrome protein (WASP) and N-WASP are critical for T cell development. Proc Natl Acad Sci USA 104:15424-15429.

Czopka T, Ffrench-Constant C, Lyons DA (2013) Individual oligodendrocytes have only a few hours in which to generate new myelin sheaths in vivo. Dev Cell 25:599-609.

Djannatian M, Timmler S, Arends M, Luckner M, Weil MT, Alexopoulos I, Snaidero N, Schmid B, Misgeld T, Mobius W, Schifferer M, Peles E, Simons M (2019) Two adhesive systems cooperatively regulate axon ensheathment and myelin growth in the CNS. Nat Commun 10:4794.

Elazar N, Vainshtein A, Rechav K, Tsoory M, Eshed-Eisenbach Y, Peles E (2019a) Coordinated internodal and paranodal adhesion controls accurate myelination by oligodendrocytes. J Cell Biol 218:2887-2895.

Elazar N, Vainshtein A, Golan N, Vijayaragavan B, Schaeren-Wiemers N, Eshed-Eisenbach Y, Peles E (2019b) Axoglial adhesion by Cadm4 regulates CNS myelination. Neuron 101:224-231. e5.

Feltri ML, Poitelon Y, Previtali SC (2016) How Schwann cells sort axons: new concepts. Neuroscientist 22:252-265.

Garcia MA, Zuchero JB (2019) Anchors away: glia-neuron adhesion regulates myelin targeting and growth. Dev Cell 51:659-661.

Gerber D, Ghidinelli M, Tinelli E, Somandin C, Gerber J, Pereira JA, Ommer A, Figlia G, Miehe M, Nageli LG, Suter V, Tadini V, Sidiropoulos PN, Wessig C, Toyka KV, Suter U (2019) Schwann cells, but not oligodendrocytes, depend strictly on dynamin 2 function. Elife 8:e42404.

Jin F, Dong B, Georgiou J, Jiang Q, Zhang J, Bharioke A, Qiu F, Lommel S, Feltri ML, Wrabetz L, Roder JC, Eyer J, Chen X, Peterson AC,
Siminovitch KA (2011) N-WASp is required for Schwann cell cytoskeletal dynamics, normal myelin gene expression and peripheral nerve myelination. Development 138:1329-1337.

Kim HJ, DiBernardo AB, Sloane JA, Rasband MN, Solomon D, Kosaras B, Kwak SP, Vartanian TK (2006) WAVE1 is required for oligodendrocyte morphogenesis and normal CNS myelination. J Neurosci 26:5849-5859.

Kluver H, Barrera E (1953) A method for the combined staining of cells and fibers in the nervous system. J Neuropathol Exp Neurol 12:400-403.

Kornfeld SF, Lynch-Godrei A, Bonin SR, Gibeault S, De Repentigny Y, Kothary R (2016) Cytoskeletal linker protein dystonin is not critical to terminal oligodendrocyte differentiation or CNS myelination. PLoS One 11:e0149201.

Lappe-Siefke C, Goebbels S, Gravel M, Nicksch E, Lee J, Braun PE, Griffiths IR, Nave KA (2003) Disruption of Cnp1 uncouples oligodendroglial functions in axonal support and myelination. Nat Genet 33:366-374.

Lunn KF, Baas PW, Duncan ID (1997) Microtubule organization and stability in the oligodendrocyte. J Neurosci 17:4921-4932.

Marques S, Zeisel A, Codeluppi S, van Bruggen D, Mendanha Falcão A, Xiao L, Li H, Häring M, Hochgerner H, Romanov RA, Gyllborg D, Muñoz Manchado A, La Manno G, Lönnerberg P, Floriddia EM, Rezayee F, Ernfors P, Arenas E, Hjerling-Leffler J, Harkany T, et al. (2016) Oligodendrocyte heterogeneity in the mouse juvenile and adult central nervous system. Science 352:1326-1329.

Misra A, Lim RP, Wu Z, Thanabalu T (2007) N-WASP plays a critical role in fibroblast adhesion and spreading. Biochem Biophys Res Commun 364:908-912.

Nave KA, Werner HB (2014) Myelination of the nervous system: mechanisms and functions. Annu Rev Cell Dev Biol 30:503-533.

Nawaz S, Sanchez P, Schmitt S, Snaidero N, Mitkovski M, Velte C, Bruckner BR, Alexopoulos I, Czopka T, Jung SY, Rhee JS, Janshoff A, Witke W, Schaap IAT, Lyons DA, Simons M (2015) Actin filament turnover drives leading edge growth during myelin sheath formation in the central nervous system. Dev Cell 34:139-151.

Novak N, Bar V, Sabanay H, Frechter S, Jaegle M, Snapper SB, Meijer D, Peles E (2011) N-WASP is required for membrane wrapping and myelination by Schwann cells. J Cell Biol 192:243-250.

Osso LA, Chan JR (2017) Architecting the myelin landscape. Curr Opin Neurobiol 47:1-7.

Rasband MN, Peles E, Trimmer JS, Levinson SR, Lux SE, Shrager P (1999) Dependence of nodal sodium channel clustering on paranodal axoglial contact in the developing CNS. J Neurosci 19:7516-7528.

Rey-Suarez I, Wheatley BA, Koo P, Bhanja A, Shu Z, Mochrie S, Song W, Shroff H, Upadhyaya A (2020) WASP family proteins regulate the mobility of the B cell receptor during signaling activation. Nat Commun 11:439.

Rohatgi R, Ho HY, Kirschner MW (2000) Mechanism of N-WASP activation by CDC42 and phosphatidylinositol 4, 5-bisphosphate. J Cell Biol 150:1299-1310.

Schindelin J, Arganda-Carreras I, Frise E, Kaynig V, Longair M, Pietzsch T, Preibisch S, Rueden C, Saalfeld S, Schmid B, Tinevez JY, White DJ, Hartenstein V, Eliceiri K, Tomancak P, Cardona A (2012) Fiji: an opensource platform for biological-image analysis. Nat Methods 9:676-682.

Seiberlich V, Bauer NG, Schwarz L, Ffrench-Constant C, Goldbaum O, Richter-Landsberg C (2015) Downregulation of the microtubule associated protein tau impairs process outgrowth and myelin basic protein mRNA transport in oligodendrocytes. Glia 63:1621-1635.

Seixas AI, Azevedo MM, Paes de Faria J, Fernandes D, Mendes Pinto I, Relvas JB (2019) Evolvability of the actin cytoskeleton in oligodendrocytes during central nervous system development and aging. Cell Mol Life Sci 76:1-11.

Snaidero N, Mobius W, Czopka T, Hekking LH, Mathisen C, Verkleij D, Goebbels S, Edgar J, Merkler D, Lyons DA, Nave KA, Simons M (2014) Myelin membrane wrapping of CNS axons by $\mathrm{PI}(3,4,5) \mathrm{P} 3$-dependent polarized growth at the inner tongue. Cell 156:277-290.

Song J, Goetz BD, Baas PW, Duncan ID (2001) Cytoskeletal reorganization during the formation of oligodendrocyte processes and branches. Mol Cell Neurosci 17:624-636.

Stadelmann C, Timmler S, Barrantes-Freer A, Simons M (2019) Myelin in the central nervous system: structure, function, and pathology. Physiol Rev 99:1381-1431. 
Takenawa T, Miki H (2001) WASP and WAVE family proteins: key molecules for rapid rearrangement of cortical actin filaments and cell movement. J Cell Sci 114:1801-1809.

Thomason EJ, Escalante M, Osterhout DJ, Fuss B (2020) The oligodendrocyte growth cone and its actin cytoskeleton: a fundamental element for progenitor cell migration and CNS myelination. Glia 68:13291346.

Thurnherr T, Benninger Y, Wu X, Chrostek A, Krause SM, Nave KA, Franklin RJ, Brakebusch C, Suter U, Relvas JB (2006) Cdc42 and Rac1 signaling are both required for and act synergistically in the correct formation of myelin sheaths in the CNS. J Neurosci 26:1011010119.

Tsuchiya D, Kitamura Y, Takata K, Sugisaki T, Taniguchi T, Uemura K, Miki H, Takenawa T, Shimohama S (2006) Developmental expression of neural Wiskott-Aldrich syndrome protein (N-WASP) and WASP family verprolin-homologous protein (WAVE)-related proteins in postnatal rat cerebral cortex and hippocampus. Neurosci Res 56:459-469.

Wang H, Tewari A, Einheber S, Salzer JL, Melendez-Vasquez CV (2008) Myosin II has distinct functions in PNS and CNS myelin sheath formation. J Cell Biol 182:1171-1184.

Zhang Y, Chen K, Sloan SA, Bennett ML, Scholze AR, O'Keeffe S, Phatnani HP, Guarnieri P, Caneda C, Ruderisch N, Deng S, Liddelow SA, Zhang C, Daneman R, Maniatis T, Barres BA, Wu JQ (2014) An RNA-sequencing transcriptome and splicing database of glia, neurons, and vascular cells of the cerebral cortex. J Neurosci 34:11929-11947.

Zuchero JB, Fu MM, Sloan SA, Ibrahim A, Olson A, Zaremba A, Dugas JC, Wienbar S, Caprariello AV, Kantor C, Leonoudakis D, LariosaWillingham K, Kronenberg G, Gertz K, Soderling SH, Miller RH, Barres BA (2015) CNS myelin wrapping is driven by actin disassembly. Dev Cell 34:152-167. 